Article

\title{
Azeotropic Distillation-Induced Self-Assembly of Mesostructured Spherical Nanoparticles as Drug Cargos for Controlled Release of Curcumin
}

\author{
Long Chen $\left.{ }^{1}{ }^{(}\right), \mathrm{Xin} \mathrm{Fu}^{2}$, Mei Lin ${ }^{3}$ and Xingmao Jiang ${ }^{1, *}$ \\ 1 Key Laboratory for Green Chemical Process of Ministry of Education, School of Chemical Engineering \& \\ Pharmacy, Wuhan Institute of Technology, Wuhan 430205, China; chenlong0729@126.com \\ 2 Nanjing Zhongwei Biomaterials Research Institute Co., Ltd., Nanjing 210008, China; tiger6105180@163.com \\ 3 Institute of Clinical Medicine, Taizhou People's Hospital Affiliated to Nantong University, \\ Taizhou 225300,CChina; 1_mei@163.com \\ * Correspondence: jxm@wit.edu.cn
}

Citation: Chen, L.; Fu, X.; Lin, M.; Jiang, X. Azeotropic

Distillation-Induced Self-Assembly of

Mesostructured Spherical

Nanoparticles as Drug Cargos for

Controlled Release of Curcumin.

Pharmaceuticals 2022, 15, 275.

https://doi.org/10.3390/ph15030275

Academic Editor: Fu-Gen Wu

Received: 11 January 2022

Accepted: 19 February 2022

Published: 23 February 2022

Publisher's Note: MDPI stays neutral with regard to jurisdictional claims in published maps and institutional affiliations.

Copyright: (C) 2022 by the authors. Licensee MDPI, Basel, Switzerland. This article is an open access article distributed under the terms and conditions of the Creative Commons Attribution (CC BY) license (https:// creativecommons.org/licenses/by/ $4.0 /)$.

\begin{abstract}
Methods of large-scale controllable production of uniform monodispersed spherical nanoparticles have been one of the research directions of scientists in recent years. In this paper, we report an azeotropic distillation-induced evaporation self-assembly method as a universal method, and monodispersed hydrophobic ordered mesoporous silica nanospheres (MHSs) were successfully synthesized by this method, using triethoxymethylsilane (MTES) as the silica precursor and hexadecyl trimethyl ammonium bromide (CTAB) as the template. SEM and TEM images showed good monodispersity, sphericity, and uniform diameter. Meanwhile, SAXS and $\mathrm{N}_{2}$ adsorption-desorption measurements demonstrated a highly ordered lamellar mesostructure with a large pore volume. The model drug, curcumin was successfully encapsulated in MHSs for drug delivery testing, and their adsorption capacity was $3.45 \mathrm{mg} \mathrm{g}^{-1}$, which greatly improved the stability of curcumin. The release time when net release rate of curcumin reached $50 \%$ was extended to 6 days.
\end{abstract}

Keywords: drug delivery; curcumin; azeotropic distillation; self-assembly; hydrophobic; mesoporous silica nanospheres

\section{Introduction}

In recent decades, drug delivery controlled by carrier systems has been demonstrated to have successful applications in the diagnosis and treatment of various diseases [1-3]. Mesostructured spherical nanoparticles are promising intracellular delivery systems for anticancer, immunomodulatory drugs and cell activity modulators, etc. [4,5]. The cellular uptake of nanoparticles by living cells is strongly size-dependent [6]. Small nanoparticle size $(\approx 50 \mathrm{~nm})$ is most efficient for the intracellular delivery [1,7]. The development of a suitable nanostructured carrier system with good biocompatibility and selective delivery of drugs to target cells is the central problem of nanomedicine. Curcumin is a natural bioactive substance, which has been of great interest to researchers due to its wide range of biological activities and pleiotropic therapeutic potential such as antioxidant, antiinflammatory [8-12], antibacterial, antifungal, antiviral, antiprotozoal, and antiparasitic activities [11,13-15], but its application has been strictly limited because of its poor solubility in water, short half-life, low bioavailability, and pharmacokinetic profile.

Compared to general organic carriers such as liposomes [16], micelles [17], PLGA [18], cyclodextrin [19], viruses, etc., mesoporous silica nanoparticles have the significant advantage of sustained release profile $[20,21]$, good biocompatibility, and large drug loading capacity, which is largely depending on their tunable surface chemistry and particle size, uniform pore size, high surface area. Therefore, mesoporous silica nanoparticles have attracted great research attention as cargos for delivery and controlled release of various drugs. Tang and co-workers found that mesoporous silica nanospheres modified 
by hydrophobic groups showed enhanced hydrothermal stability and delayed release of hydrophobic drug [22]. Highly monodispersed mesoporous silica nanospheres are needed to control the delivery rate [23]. While the method of large-scale controllable production of uniform monodispersed spherical nanoparticles has been one of the research directions of scientists in recent years. Brinker and his co-workers succeeded in fabricating mesoporous silica nanospheres by developed aerosol-assisted evaporation-induced selfassembly (EISA) progress [24]. The monodispersed spherical silica nanoparticles can be obtained after a few seconds of EISA progress, which greatly improves the production efficiency. Various templates (CTAB, Brij-56, Brij-58, P123) have been used to control the pore size and mesostructures of silica [25]. Then, they synthesized protocells by fusion of lipid bilayers to the mesoporous silica nanospheres, and this structure was prominent for drug delivery [1,3,5,26-29]. However, mesoporous silica nanospheres made using a commercial atomizer (Model 3076, TSI, Inc., St Paul, MN, USA) have a wide size distribution ( 50-1000 nm), requiring separation. Although the electrospray aerosol generator (Model 3480, TSI, Inc., St Paul, MN, USA) can produce high concentrations of monodisperse submicron particles with diameters ranging from $2 \mathrm{~nm}$ to $100 \mathrm{~nm}$ [30], its yield is too low (Liquid flow rate: 50 to $100 \mathrm{~nL} \mathrm{~min}^{-1}$ ). Large-scale controllable production of MHSs with uniform particle size by aerosol-induced EISA is still a challenge.

Here, we report a facile synthesis method based on azeotropic distillation-induced self-assembly to prepare MHSs with good monodispersity and controllable uniform size. This method is easy to operate, and can solve the deficiencies in the synthesis of MHSs by aerosol-assisted EISA, such as wide size distribution, small specific surface area and pore volume. In addition, it can be used for the synthesis of many functional nanomaterials, and can be effectively applied to large-scale industrial production. In this report, the water, ethanol, benzene and CTAB form a stable reverse microemulsion under stirring and MTES has enough time to be hydrolyzed after adding to the system. The rising temperature causes the solvent to evaporate as an azeotrope, then the water phase and benzene will be condensed, the water phase can be separated by a water separator, and the benzene can reflux back to the reaction system. Each MHS can be formed from one single aqueous droplet in the microemulsion after evaporation and removal of water. The usual aerosolassisted EISA is not able to synthesis of hydrophobic ordered porous silica with MTES, due to the fast evaporation and hydrolysis rate which cannot match with slow self-assembly rate of MTES. As a result, the relatively slow evaporation rate of azeotropic distillation is necessary for continuous self-assembly of MTES into highly ordered porous structures.

\section{Results}

\subsection{Characterization of MHS Samples}

Field emission scanning electron microscopy (FESEM) and transmission electron microscopy (TEM) images of the washed and dried MHS samples are shown in Figure 1 . The MHS samples are uniform in size and spherical in shape (Figure 1a,b,d), and their particle size could be adjusted by the amount of CTAB/MTES mole ratio (Table 1). The particle size of MHS-1 was about $30 \mathrm{~nm}$, while the particle size of MHS-2 is about $132 \mathrm{~nm}$, because of the CTAB/MTES mole ratio of MHS-2 is lower. From the HRTEM image of MHS-1 (Figure 1c), CTAB produces particles exhibiting a highly ordered lamellar mesostructure.

To determine the pore ordering of the synthesized MHS samples, Small Angle X-ray Scattering (SAXS) analysis was performed from $0.8^{\circ}$ to $12^{\circ}$ (Figure 2). MHS-1 and MHS-2 showed sharp peaks at a low angle $\left(2 \theta=3.41^{\circ}\right)$ and two weak peaks at higher angles (2 $\theta=6.81^{\circ}$ and $10.18^{\circ}$ ) corresponding to the (100), (200), and (300) planes, respectively. The SAXS curve of MHS-1 shows that the washed and dried particles have an ordered lamellar structure. Compared to MHS-1, due to the decrease of CTAB/MTES mole ratio, it is difficult for silica-surfactant liquid-crystalline mesophase to grow in an orderly fashion in the process of self-assembly induced by azeotropic distillation, which leads the structural order of MHS-2 to decrease. 


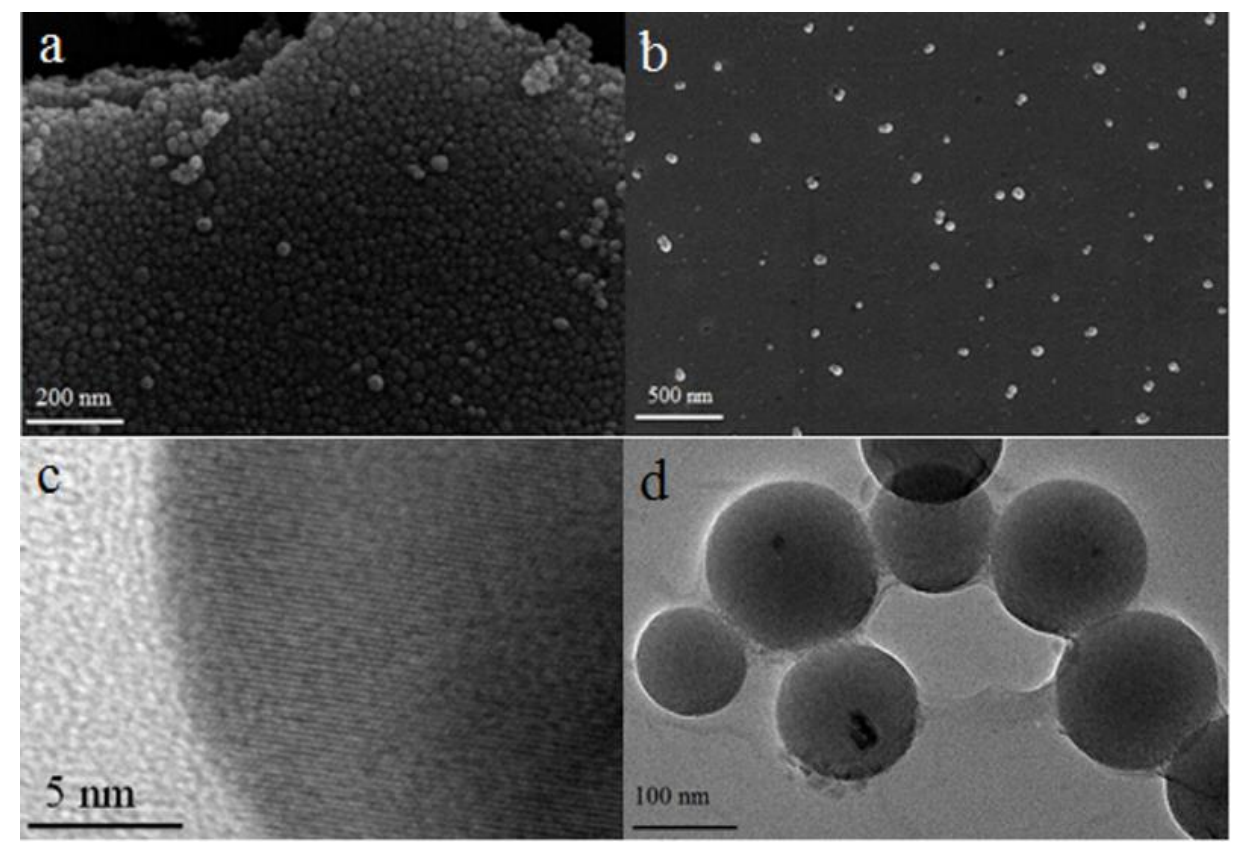

Figure 1. (a,b) FESEM images of MHS-1 sample (original magnification = 20,000 $\times$ ), (c) HRTEM image of MHS-1 sample, (d) TEM image of MHS-2 sample.

Table 1. Physicochemical characteristics of MHS samples ${ }^{a}$.

\begin{tabular}{cccccc}
\hline Sample & C/M MR & MD (nm) & PV $\left(\mathbf{c m}^{\mathbf{3}} \mathbf{g}^{-\mathbf{1}}\right)$ & SA $_{\text {BET }}\left(\mathbf{m}^{\mathbf{2}} \mathbf{g}^{-\mathbf{1}}\right)$ & PD (nm) \\
\hline MHS-1 & 2.75 & 30 & 1.208 & 477.002 & 4.3110 \\
MHS-2 & 0.183 & 132 & 0.654 & 257.452 & 12.4022 \\
\hline
\end{tabular}

a C/M MR: CTAB/MTES mole ratio, MD: Mean diameter, PV: Pore volume, $\mathrm{SA}_{\mathrm{BET}}$ : BET surface area, PD: Pore diameter.

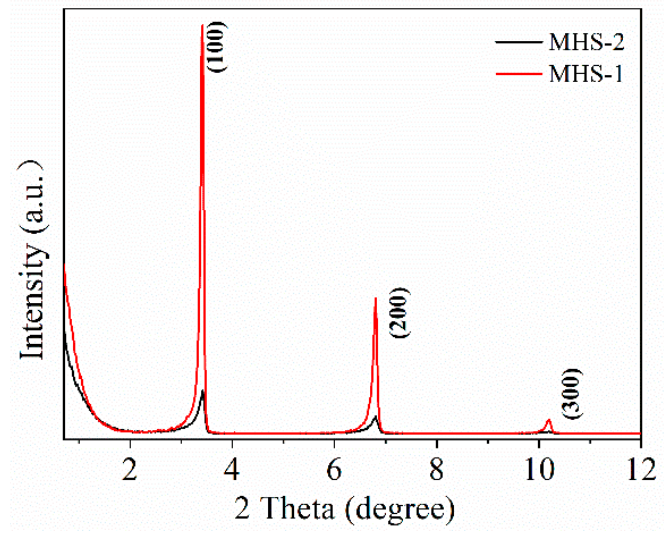

Figure 2. Small angle X-ray scattering (SAXS) curves of MHS-1 and MHS-2.

Figure 3 shows the $\mathrm{N}_{2}$ adsorption-desorption isotherms and the pore size distribution curve for washed and dried MHS-1 and MHS-2 samples. The samples were outgassed at $250{ }^{\circ} \mathrm{C}$ for $10 \mathrm{~h}$ before measurements. The MHS-1 (Figure 3a) exhibited a typical type IV isotherm with a H4 hysteresis loop, giving a large pore volume $\left(1.208 \mathrm{~cm}^{3} \mathrm{~g}^{-1}\right)$ and a narrow pore size distribution (centered at $4.3110 \mathrm{~nm}$ ) (Table 1). In Figure 3b, MHS-2 showed a type III isotherm with a H3 hysteresis loop, indicating that the pore size is non-uniform, and compared with MHS-1, its pore volume $\left(0.654 \mathrm{~cm}^{3} \mathrm{~g}^{-1}\right)$ and the surface area $\left(257.452 \mathrm{~m}^{2} \mathrm{~g}^{-1}\right)$ drastically decreased (Table 1). This was attributed to the fact that the CTAB/MTES mole ratio decreased, and the structural order of MHS-2 decreased. This is consistent with the results of SAXS analysis. All results mentioned above further 
demonstrate that MHS-1 with a smaller size, uniform pore size and higher specific area is more suitable for hydrophobic drug storage and release.
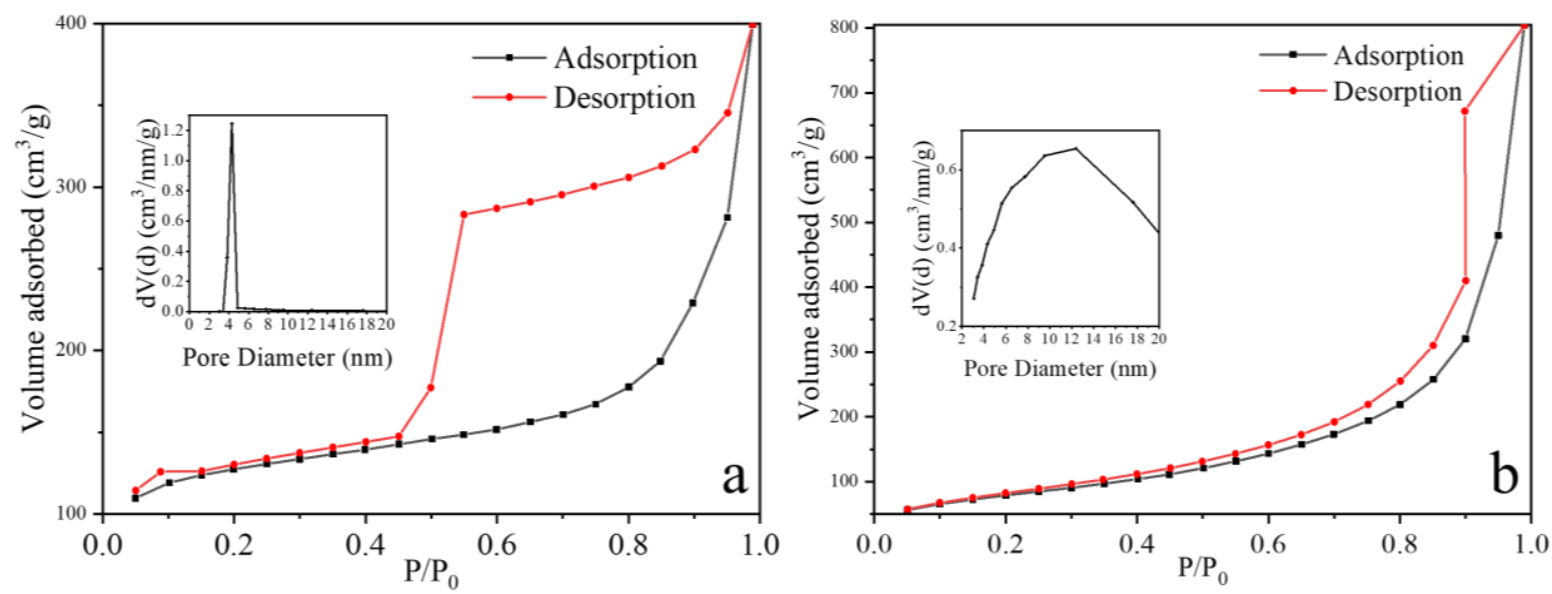

Figure 3. $\mathrm{N}_{2}$ adsorption-desorption isotherms corresponding pore size distribution curve of (a) MHS1 sample and (b) MHS-2 sample.

The surface properties of washed MHS-1 and MHS-2 samples with different heat treatment temperatures were measured by the contact angle test in Figure 4 . Tablets of MHSs were prepared using a cylindrical stainless-steel die with a diameter of $1 \mathrm{~cm}$. A pressure of 15 bar was applied for 10 min using a manual hydraulic press. The contact angle results of washed MHS- 1 and MHS- 2 dried at $60{ }^{\circ} \mathrm{C}$ were $121.2^{\circ}$ and $120.5^{\circ}$ (Figure $4 \mathrm{a}, \mathrm{c}$ ), which showed that the silica has good hydrophobic property. The contact angle of the particles increased to $126.3^{\circ}$ and $129.9^{\circ}$ (Figure $4 \mathrm{~b}, \mathrm{~d}$ ) after increasing drying temperature to $300{ }^{\circ} \mathrm{C}$, indicating that the free water and hydroxyl groups on the surface of MHS samples decreased with the increase of temperature. The thermal, chemical and physical properties of MHS-1 and MHS-2 were measured at different atmosphere by simultaneous thermogravimetry and differential scanning calorimetry (TG-DSC) in $\mathrm{N}_{2}$ (Figure 5a,c) or air (Figure $5 b, d$ ) at a constant heating rate of $10{ }^{\circ} \mathrm{C} \mathrm{min}^{-1}$ in the temperature range between $30{ }^{\circ} \mathrm{C}$ and $800^{\circ} \mathrm{C}$. Compared with the data under $\mathrm{N}_{2}$ conditions, one strong exothermic peak appeared at $420^{\circ} \mathrm{C}$ under air conditions, suggesting oxidation of methyl groups by oxygen. This result demonstrated a high thermal stability for MHSs. The mesopores were covered by lipophilic- $\mathrm{CH}_{3}$ groups, enabling curcumin molecules to easily enter and stay in the pores.

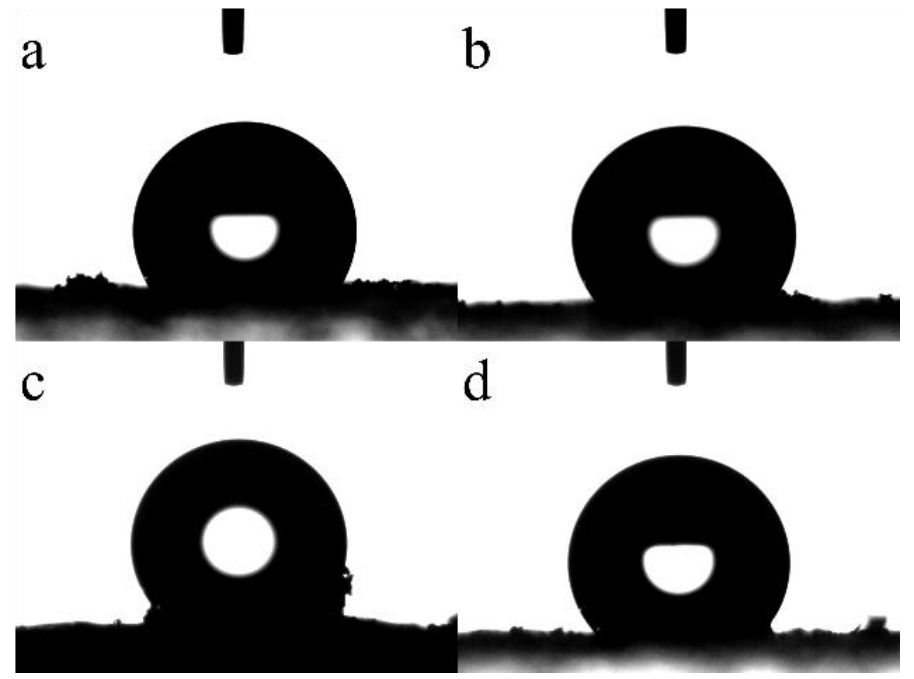

Figure 4. Contact angle measurements of MHS-1 and MHS-2 samples were dried at $(\mathbf{a}, \mathbf{c}) 60^{\circ} \mathrm{C}$ and (b,d) $300^{\circ} \mathrm{C}$. 

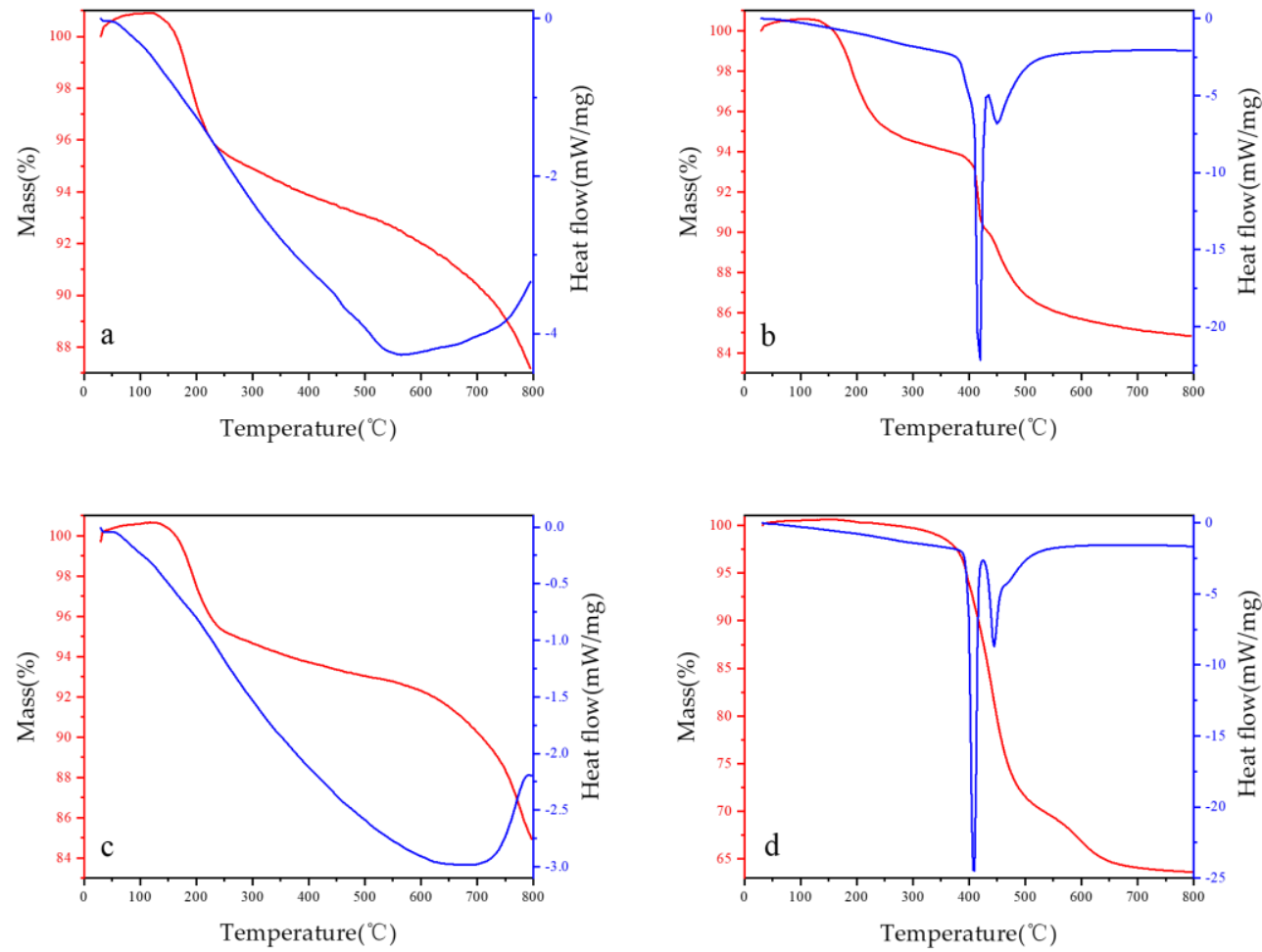

Figure 5. TG-DSC curves for MHS-1 and MHS-2 calcined under $(\mathbf{a}, \mathbf{c}) \mathrm{N}_{2}$ or $(\mathbf{b}, \mathbf{d})$ air with a heating rate of $10^{\circ} \mathrm{C} \mathrm{min}^{-1}$.

\subsection{Adsorption and Release Experiment of Curcumin}

After loading with curcumin, MHS- 1 and MHS- 2 were accordingly marked as MHSAC1 and MHSAC-2, respectively. Figure 6 showed the FTIR spectra of MHS-1, MHSAC-1, MHS-2, MHSAC-2 and curcumin samples. The FTIR peaks in the ranges of $1026-1125 \mathrm{~cm}^{-1}$, $772-801 \mathrm{~cm}^{-1}$ and $434-441 \mathrm{~cm}^{-1}$ correspond to the asymmetric, symmetric stretching and bending modes of the Si-O-Si [31], respectively (I and III in Figure 6). A sharp peak appearing at $2974 \mathrm{~cm}^{-1}$ can be assigned to $-\mathrm{CH}_{3}$ group and an absorption peak at $1275 \mathrm{~cm}^{-1}$ belongs to $\mathrm{Si}-\mathrm{CH}_{3}$ stretching vibrations [31]. The FTIR peaks at $3468 \mathrm{~cm}^{-1}$ belong to $\mathrm{OH}$ groups of $\mathrm{Si}-\mathrm{OH}$ on the surface of the MHS samples. In the FTIR spectra for curcumin (V in Figure 6), a sharp peak at $3511 \mathrm{~cm}^{-1}$ is assigned to the phenolic O-H stretching with a broad band at a range from $3100-3400 \mathrm{~cm}^{-1}$, which is due to the -OH group (in enol form). The strong peak at $1627 \mathrm{~cm}^{-1}$ is associated with mixed $\mathrm{C}=\mathrm{O}$ and $\mathrm{C}=\mathrm{C}$ species of curcumin. Another strong band at $1603 \mathrm{~cm}^{-1}$ is attributed to the symmetric aromatic ring stretching vibrations $C=C$ ring. The $1509 \mathrm{~cm}^{-1}$ peak is assigned to the $C=O$, and the $C-O-C$ stretching peak of ether at $1027 \mathrm{~cm}^{-1}$ [32]. After curcumin was adsorbed, a new absorption band belonging to the heptadiene-dione chromophore group of curcumin appeared in the range of $1429-1627 \mathrm{~cm}^{-1}$ (II and IV in Figure 6). Other FTIR peaks belonging to MHS samples had no obvious shift. These results suggested that curcumin molecule had been adsorbed to hydrophobic silica [33]. It was also found that the absorption band intensity at $1429-1627 \mathrm{~cm}^{-1}$ of MHSAC-1 sample was much stronger than that of MHSAC-2 sample as a result of more curcumin loaded in MHSAC-1. All these results demonstrate that curcumin was successfully encapsulated in the as-synthesized MHS-1 samples.

Curcumin was encapsulated in hydrophobic mesopores by repeated heating and cooling of curcumin solution $\left(\mathrm{V}_{\text {water }}: \mathrm{V}_{\text {ethanol }}=1: 1\right)$ and MHS samples [34]. The remaining curcumin solutions after removal of MHSAC-1 and MHSAC-2, were accordingly marked as C-1 and C-2, respectively. Figure 7a shows the UV-vis spectra of $3.94 \mathrm{mg} \mathrm{L}^{-1}$ curcumin solution, C-1 and C-2. A sharp absorption peak of curcumin in a mixed solution of water and ethanol $\left(\mathrm{V}_{\text {water }}: \mathrm{V}_{\text {ethanol }}=1: 1\right)$ appeared at $432 \mathrm{~nm}$. A series of curcumin solutions with different concentration were prepared, and their absorbance at $432 \mathrm{~nm}$ was measured to 
obtain the standard curve of curcumin solution (Figure $7 \mathrm{~b}$ ). After curcumin was adsorbed, the intensity of the absorption peaks for C-1 and C-2 decreased as a result of attachment of curcumin to the MHS-1 and MHS-2. C-1 exhibited a much lower absorption peak than C-2, indicating that higher adsorption capacity of MHS-1 due to larger specific area and pore volume under the same conditions. After calculation, the curcumin adsorption capacity of MHS- 1 was $3.45 \mathrm{mg} \mathrm{g}^{-1}$, while it was only $0.91 \mathrm{mg} \mathrm{g}^{-1}$ for MHS-2. It was proved that a mesoporous carrier with a high specific surface area, large pore volume, and appropriate pore size (larger than the kinetic diameter of the drug) would be beneficial for improving the adsorption capacity.
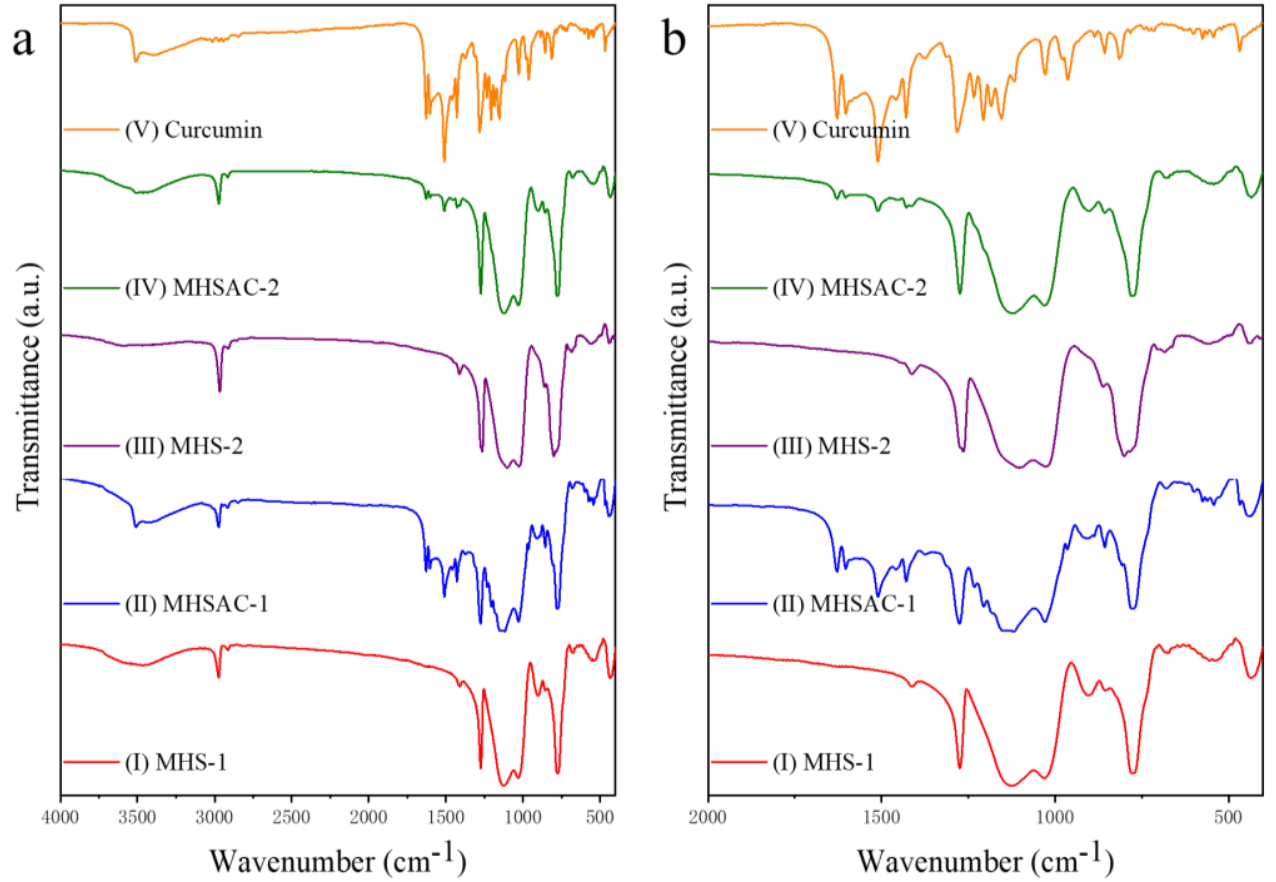

Figure 6. FTIR spectra for MHS-1, MHSAC-1, MHS-2, MHSAC-2 and curcumin: (a) range from $4000 \mathrm{~cm}^{-1}$ to $400 \mathrm{~cm}^{-1}$, (b) range from $2000 \mathrm{~cm}^{-1}$ to $400 \mathrm{~cm}^{-1}$.
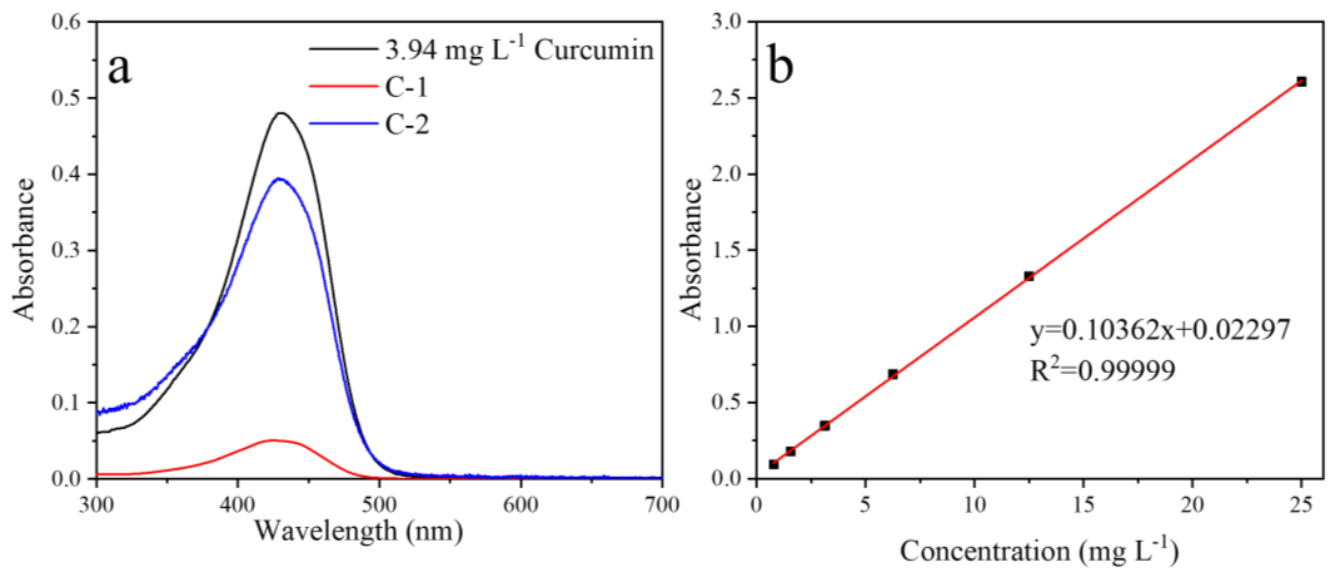

Figure 7. (a) UV-vis spectra of $3.94 \mathrm{mg} \mathrm{L}^{-1}$ curcumin mixed solution $\left(\mathrm{V}_{\text {water }}: \mathrm{V}_{\text {ethanol }}=1: 1\right), \mathrm{C}-1$ and C-2, (b) standard curve of curcumin.

As shown in Figure 8a, the in vitro sustained release process of curcumin was investigated by means of UV-vis spectroscopy. Curcumin was released from MHSAC-1 for 21 days in phosphate-buffered saline (PBS, water, $\mathrm{pH}=7.4$ ). Figure $8 \mathrm{~b}$ shows the in vitro release kinetics of curcumin from MHSAC-1 samples in PBS (water, $\mathrm{pH}=7.4$ ), which was calculated according to the standard curve of curcumin in Figure $7 \mathrm{~b}$. As shown, 70.6\% 
of absorbed curcumin released slowly from MHSAC-1 samples in PBS, which lasted for 21 days. On about the sixth day, the net release rate of curcumin just reached $50 \%$ and then then rate of release became slow. It was important to extend the release time for practical controlled release. These results proved that the MHS nanospheres with a small size, larger specific area and pore volume (MHSAC-1) displayed a sustained release of curcumin and have great application potential in the study on the controllable slow release of hydrophobic drugs.
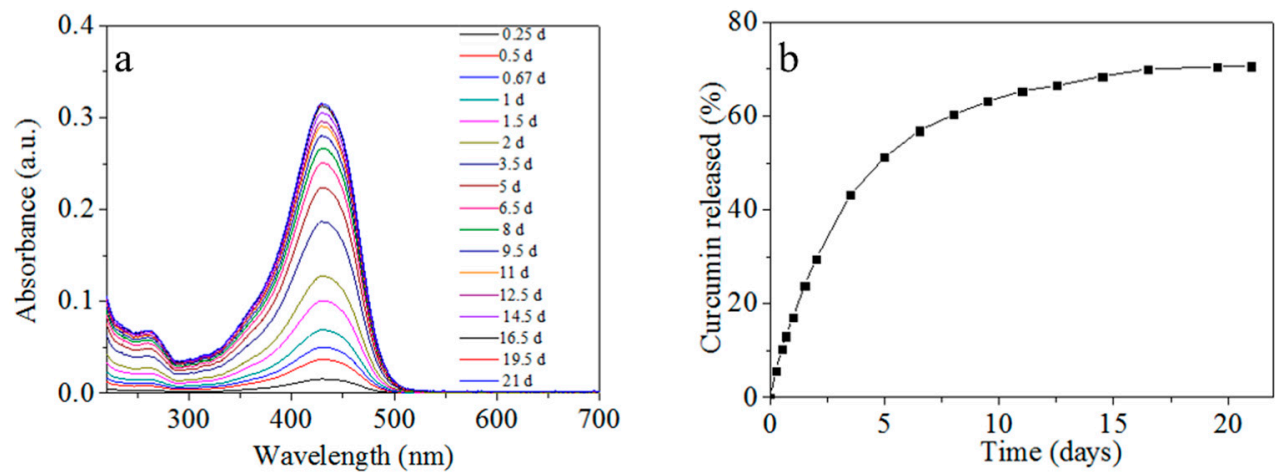

Figure 8. (a) UV-vis spectra of curcumin PBS (water, $\mathrm{pH}=7.4$ ) at different release times from MHSAC-1. (b) The curcumin release curve of MHSAC-1 samples in PBS (water, $\mathrm{pH}=7.4$ ).

\section{Discussion}

Usually, because the atomization process is uncontrollable, the diameter distribution of aerosol droplets obtained by commercial atomizers (such as Model 3076, TSI, Inc., St Paul, MN, USA) is wide. Therefore, it is difficult to achieve uniformity of as-synthesized particle size. Some scholars have added a microwave radiation zone at the back end of commercial atomizers to cause aerosol droplets to break up due to overheating under microwave radiation. Due to the surface tension of droplets, it will make the aerosol droplets in the carrier gas maintain the maximum total contact area and minimize the Gibbs free energy, so that the particle size of the droplets entering the drying zone tends to be uniform.

The self-assembly induced by azeotropic distillation is designed based on this principle. On the one hand, it has some similarities with aerosol-assisted self-assembly, beginning with a homogeneous solution of soluble silica and surfactant prepared in ethanol/water solvent with $\mathrm{c}_{0}<<$ critical micelle concentration $(\mathrm{cmc})$. CTAB as a stabilizer [35] can disperse the water phase into small droplets with uniform size in the oil phase. Additionally, due to the surface tension of the droplets, this stirred and heated system tends to maintain the maximum total contact area, which can cause the Gibbs free energy to be the lowest. The hydrolysis of MTES in the droplets is controlled, which limits the excessive growth of silica particles. With the slow separation of the water phase in the azeotrope and the reflux of benzene, the evaporation of the solvent creates a radial gradient of surfactant concentration from surface of each droplet to inside that steepens in time [36]. As the surfactant on the droplet surface first reaches the critical micelle concentration $(\mathrm{cmc})$ [24], the ordered silica-surfactant liquid-crystalline mesophase grows radially inward from the surface. Finally, as the solvent continues to decrease, the silica-surfactant mesophase dries and shrinks to a sphere. For all the nanoparticles that can be synthesized by aerosol-assisted self-assembly, the self-assembly induced by azeotropic distillation can be applied, and the uniformity of particles can be ensured.

On the other hand, it is also different from aerosol-assisted self-assembly. Azeotropic distillation can adjust the evaporation rate of azeotrope by controlling the temperature of the system. In a typical synthesis, it takes about $0.5 \mathrm{~h}$ to get $0.5 \mathrm{~mL}$ of condensed azeotrope, and all ethanol and water in the system can be separated for as long as several hours (It only takes a few seconds for ethanol and water to evaporate in the process of aerosolassisted self-assembly). This ensures that there is sufficient time for ordered self-assembly of MTES and CTAB liquid crystal mesophase. Therefore, this method can also be used 
to synthesize some nanoparticles with special morphology, such as cube shape [37] and rod shape. Of course, the self-assembly process induced by azeotropic distillation also has some shortcomings. The system is an inverse microemulsion system which depends on stirring to achieve uniform dispersion. Stirring speeds that are too violent or too slow may lead to irregular morphology of the final particles.

The MHSs prepared by self-assembly induced by azeotropic distillation show a good ability to control the sustained release of hydrophobic drugs. The release time at which the net release rate of curcumin reached $50 \%$ was extended to 6 days, which was much slower than curcumin-conjugated silica nanoparticles $(7 \mathrm{~h})$ [33], L- methionine encapsulated by hollow mesoporous silica nanoparticles (50 $\mathrm{min}$ ) [34], and curcumin loaded by mesoporous silica nanoparticles (functionalized by 3-aminopropyltriethoxyorthosilane) $(50 \mathrm{~h})$ [38] These results prove that this material can also be expected to be used in the encapsulation of other fat-soluble drugs, such as taxol, methotrexate, doxorubicin, etc.

\section{Materials and Methods}

\subsection{Reagents and Instruments}

All reagent-grade chemicals were used as received without further purification, and ultra nanopure distilled water $(18.25 \mathrm{M} \Omega \cdot \mathrm{cm})$ was used in all experiments. Curcumin, triethoxymethylsilane (MTES) and hexadecyl trimethyl ammonium bromide (CTAB) were purchased from Shanghai Aladdin Biochemical Technology Co., Ltd. (Shanghai, China). Ethanol, isopropyl alcohol, and benzene were bought from Sinopharm Chemical Reagent Co., Ltd. (Shanghai, China).

X-ray powder diffraction (XRD) patterns were recorded on a Rigaku Ultima IV powder diffractometer with a $\mathrm{Cu} \mathrm{K} \alpha$ radiation source $(\lambda=1.5406 \AA$, $40 \mathrm{kV}, 100 \mathrm{~mA})$. Field emission scanning electron microscopy (FESEM, SIGMA Zeiss, Germany) and transmission electron microscopy (TEM, FEI Tecnai 30, $300 \mathrm{kV}$, Philips) were applied for characterization of the morphology of the samples. Fourier transform infrared spectroscopy (FTIR) were measured with a Tensor-II spectrometer (Bruker Co., Germany) by averaging 64 scans with a spatial resolution of $4 \mathrm{~cm}^{-1}$. UV-vis absorption spectra were measured by Shimadzu UV-3600 UV-Vis-NIR spectrophotometer. The contact angles were measured by the XG-CAMA static contact angle tester. Thermal behavior of the samples was analyzed by thermogravimetry and differential scanning calorimetry (TG/DSC) (NETZSCH STA 409 PC, Germany). Labsys Evo simultaneous thermal analyzer was used to test the thermal stability of mesoporous hydrophobic silica. BET-surface area was measured by $\mathrm{N}_{2}$ adsorption-desorption at liquid nitrogen temperature using an Autosorb-iQ2-MP (Quantachrome) gas sorption system. Specific surface areas were calculated using the Brunauer-Emmett-Teller (BET) model, and the pore size distributions were evaluated from the adsorption branches of the nitrogen isotherms using the Barrett-Joyner-Halenda (BJH) model.

\subsection{Synthesis of MHS Samples}

MHS samples were synthesized by azeotropic distillation-induced self-assembly, as defined in Scheme 1. In a typical synthesis, MHS-1 was prepared as follows: $1 \mathrm{~g}$ CTAB was dissolved in a solution of $7.5 \mathrm{~mL}$ deionized water, $18.5 \mathrm{~mL}$ ethanol and $74 \mathrm{~mL}$ benzene. The mixture was poured into a $250 \mathrm{~mL}$ three-necked flask mounted with a Dean-Stark trap followed by stirring at room temperature for $30 \mathrm{~min}$ to form a reverse microemulsion. Then $0.2 \mathrm{~mL}$ MTES was added into the above solution, which was kept at $45^{\circ} \mathrm{C}$ for $2 \mathrm{~h}$. With the hydrolysis of MTES molecules and formation of silanols, silica species became more hydrophilic and enriched in the aqueous droplets as a result of phase equilibrium. With constant hydrolysis of MTES and the enhanced hydrophilic of silica precursors, silica species continuously diffused from the benzene phase into water-ethanol droplets due to decreased solubility. Evaporation of water and ethanol from the droplets by azeotropic distillation at $64.9^{\circ} \mathrm{C}$ (azeotrope composition: ethanol 18.5\%, benzene $74 \%$ and water $7.5 \%$ ) increased the concentrations of the silica species and CTAB, which led to self-assembly of the micelles into liquid crystalline mesophase. Meanwhile, hydrophilic inorganic precursors 
were also condensed into ordered porous silica with the liquid crystal as templates. The solution was then heated to $115^{\circ} \mathrm{C}$ to remove the solvent. Subsequently, the samples were cooled to room temperature, collected and washed with a solution (deionized water and isopropyl alcohol, the volume ratio of $1: 1$ ) to remove the CTAB, and further dried at $60{ }^{\circ} \mathrm{C}$ for $6 \mathrm{~h}$. The preparation process for MHS-2 is the same as for MHS-1 except for adding $3 \mathrm{~mL}$ MTES instead of $0.2 \mathrm{~mL}$ MTES.

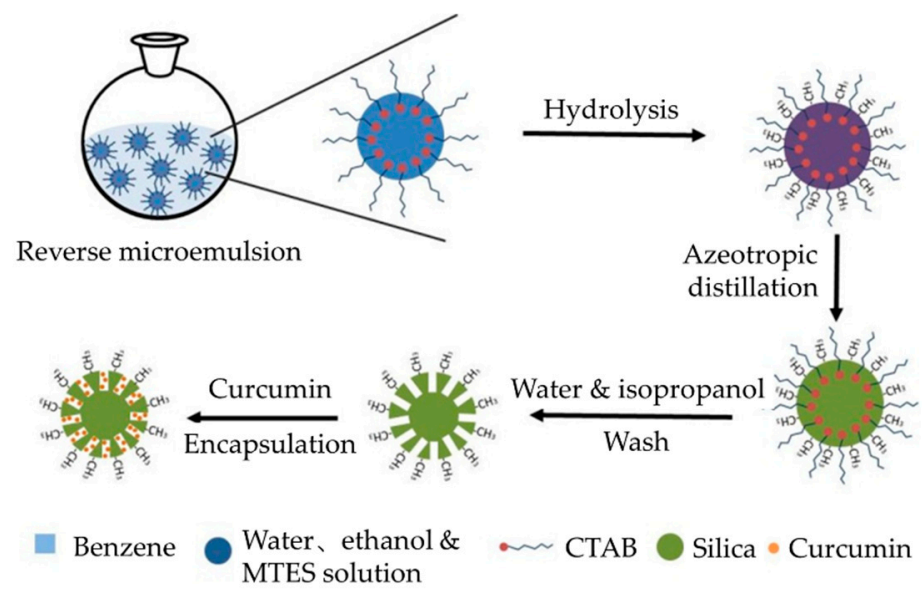

Scheme 1. Schematic diagram of the azeotropic distillation assisted route for formation of mesoporous hydrophobic silica nanospheres.

\subsection{Adsorption and Release Experiment of Curcumin}

MHSAC-1 was prepared as follows: $0.1 \mathrm{~g}$ MHS-1 was dissolved in $100 \mathrm{~mL} 3.94 \mathrm{mg} \mathrm{L}-1$ curcumin solution $\left(\mathrm{V}_{\text {water }}: \mathrm{V}_{\text {ethanol }}=1: 1\right)$, followed by repeated heating and cooling several times until the color of the solution did not change. The samples were collected by centrifugation at $13000 \mathrm{rpm}$ for $10 \mathrm{~min}$ and dried at $60{ }^{\circ} \mathrm{C}$ for $1 \mathrm{~h}$. The preparation process for MHSAC-2 is the same as for MHSAC-1. The in vitro release kinetics of curcumin from MHSAC was as follows: Sixteen MHSAC samples of $0.01 \mathrm{~g}$ each were dissolved in $10 \mathrm{~mL}$ phosphate-buffered saline (PBS, water, $\mathrm{pH}$ 7.4). Then these samples were stirred at $100 \mathrm{rpm}$ with a magnetic stirrer at $37^{\circ} \mathrm{C}$. After a period of time, the solution was centrifuged at $7000 \mathrm{rpm}$ for $3 \mathrm{~min}$ to separate curcumin from the bottom of phosphate-buffered saline. The separated curcumin was dissolved in $10 \mathrm{~mL}$ mixed solution $\left(\mathrm{V}_{\text {water }}: \mathrm{V}_{\text {ethanol }}=1: 1, \mathrm{pH} 7.0\right)$ then the UV-vis absorption spectra were recorded.

\section{Conclusions}

In summary, ordered mesoporous hydrophobic silica nanoparticles (MHSs) with a uniform size were successfully one-step synthesized by an azeotropic distillation-assisted method with MTES as precursor and CTAB as an ordered mesoporous template. The obtained MHSs exhibited high monodispersity, good sphericity, and large pore volume, with a highly ordered lamellar mesostructure, while the particle size can also be adjusted. This method solved the deficiencies in the synthesis of MHSs by aerosol-assisted EISA, such as wide size distribution, and small specific surface area and pore volume. Curcumin was successfully encapsulated in MHSs, and their adsorption capacity was $3.45 \mathrm{mg} \mathrm{g}^{-1}$, greatly improving the stability of curcumin. The release time after which net release rate of curcumin reached 50\% was extended to 6 days. Curcumin can be released slowly from MHSs, guaranteeing that curcumin has enough time to reach and inhibit cancer cells, bacteria, fungus, etc. MHSs also have great application potential in the study on the encapsulation of other hydrophobic drugs for drug delivery such as taxol, methotrexate, doxorubicin, etc. 


\section{Patents}

There was a patent (Patent number: CN104876230B) resulting from the work reported in this manuscript and it was licensed.

Author Contributions: Conceptualization, L.C. and X.J.; methodology, L.C., X.F., M.L. and X.J.; investigation, L.C., X.F., M.L. and X.J.; software, resources and visualization, L.C. and X.F.; literature search, L.C. and X.F.; writing-original draft preparation, L.C. and X.F.; writing-review and editing, L.C., X.F., M.L. and X.J.; funding acquisition, M.L. and X.J. All authors have read and agreed to the published version of the manuscript.

Funding: This research was financially supported by the National Natural Science Foundation of China (NO.21878237) and the Graduate Innovative Fund of Wuhan Institute of Technology (NO. CX2020018).

Institutional Review Board Statement: Not applicable.

Informed Consent Statement: Not applicable.

Data Availability Statement: Data is contained within the article.

Acknowledgments: We record our sincere thanks for the measurement provided by Key Laboratory for Green Chemical Process of Ministry of Education, School of Chemical Engineering \& Pharmacy, Wuhan Institute of Technology, Wuhan, China. In addition, also many thanks for the curcumin provided by Institute of Clinical Medicine, Taizhou People's Hospital Affiliated to Nantong University, Taizhou, Jiangsu 225300, China.

Conflicts of Interest: The authors declare no conflict of interest.

\section{References}

1. Ashley, C.E.; Carnes, E.C.; Phillips, G.K.; Padilla, D.; Durfee, P.N.; Brown, P.A.; Hanna, T.N.; Liu, J.; Phillips, B.; Carter, M.B.; et al. The targeted delivery of multicomponent cargos to cancer cells by nanoporous particle-supported lipid bilayers. Nat. Mater. 2011, 10, 389-397. [CrossRef] [PubMed]

2. Langer, R. Polymer-controlled drug delivery systems. Acc. Chem. Res. 1993, 26, 537-542. [CrossRef]

3. Liu, J.; Stace-Naughton, A.; Jiang, X.; Brinker, C.J. Porous nanoparticle supported lipid bilayers (protocells) as delivery vehicles. J. Am. Chem. Soc. 2009, 131, 1354-1355. [CrossRef]

4. Tarn, D.; Ashley, C.E.; Xue, M.; Carnes, E.C.; Zink, J.I.; Brinker, C.J. Mesoporous silica nanoparticle nanocarriers: Biofunctionality and biocompatibility. Acc. Chem. Res. 2013, 46, 792-801. [CrossRef] [PubMed]

5. Liu, J.; Stace-Naughton, A.; Brinker, C.J. Silica nanoparticle supported lipid bilayers for gene delivery. Chem. Commun. 2009, 5100-5102. [CrossRef]

6. Zhang, S.; Li, J.; Lykotrafitis, G.; Bao, G.; Suresh, S. Size-dependent endocytosis of nanoparticles. Adv. Mater. 2009, 21, 419-424. [CrossRef]

7. Jiang, W.; Kim, B.Y.; Rutka, J.T.; Chan, W.C. Nanoparticle-mediated cellular response is size-dependent. Nat. Nanotechnol. 2008, 3, 145-150. [CrossRef]

8. Pan, Y.; Chen, Y.; Li, Q.; Yu, X.; Wang, J.; Zheng, J. The synthesis and evaluation of novel hydroxyl substituted chalcone analogs with in vitro anti-free radicals pharmacological activity and in vivo anti-oxidation activity in a free radical-injury Alzheimer's model. Molecules 2013, 18, 1693-1703. [CrossRef]

9. Hatcher, H.; Planalp, R.; Cho, J.; Torti, F.; Torti, S. Curcumin: From ancient medicine to current clinical trials. Cell. Mol. Life Sci. 2008, 65, 1631-1652. [CrossRef]

10. Liu, Z.; Tang, L.; Zou, P.; Zhang, Y.; Wang, Z.; Fang, Q.; Jiang, L.; Chen, G.; Xu, Z.; Zhang, H.; et al. Synthesis and biological evaluation of allylated and prenylated mono-carbonyl analogs of curcumin as anti-inflammatory agents. Eur. J. Med. Chem. 2014, 74, 671-682. [CrossRef]

11. Zorofchian Moghadamtousi, S.; Abdul Kadir, H.; Hassandarvish, P.; Tajik, H.; Abubakar, S.; Zandi, K. A review on antibacterial, antiviral, and antifungal activity of curcumin. BioMed Res. Int. 2014, 2014, 186864. [CrossRef] [PubMed]

12. Hewlings, S.J.; Kalman, D.S. Curcumin: A review of its effects on human health. Foods 2017, 6, 92. [CrossRef]

13. Praditya, D.; Kirchhoff, L.; Brüning, J.; Rachmawati, H.; Steinmann, J.; Steinmann, E. Anti-infective properties of the golden spice curcumin. Front. Microbiol. 2019, 10, 912. [CrossRef] [PubMed]

14. Rai, M.; Ingle, A.P.; Pandit, R.; Paralikar, P.; Anasane, N.; Santos, C.A.D. Curcumin and curcumin-loaded nanoparticles: Antipathogenic and antiparasitic activities. Expert Rev. Anti-Infect. Ther. 2020, 18, 367-379. [CrossRef] [PubMed]

15. Adamczak, A.; Ożarowski, M.; Karpiński, T.M. Curcumin, a natural antimicrobial agent with strain-specific activity. Pharmaceuticals 2020, 13, 153. [CrossRef] [PubMed] 
16. Akbarzadeh, A.; Rezaei-Sadabady, R.; Davaran, S.; Joo, S.W.; Zarghami, N.; Hanifehpour, Y.; Samiei, M.; Kouhi, M.; Nejati-Koshki, K. Liposome: Classification, preparation, and applications. Nanoscale Res. Lett. 2013, 8, 102. [CrossRef]

17. Yoo, J.-W.; Irvine, D.J.; Discher, D.E.; Mitragotri, S. Bio-inspired, bioengineered and biomimetic drug delivery carriers. Nat. Rev. Drug Discov. 2011, 10, 521-535. [CrossRef]

18. Yallapu, M.M.; Gupta, B.K.; Jaggi, M.; Chauhan, S.C. Fabrication of curcumin encapsulated PLGA nanoparticles for improved therapeutic effects in metastatic cancer cells. J. Colloid Interface Sci. 2010, 351, 19-29. [CrossRef]

19. Yallapu, M.M.; Jaggi, M.; Chauhan, S.C. $\beta$-Cyclodextrin-curcumin self-assembly enhances curcumin delivery in prostate cancer cells. Colloids Surf. B Biointerfaces 2010, 79, 113-125. [CrossRef]

20. Choi, E.; Lu, J.; Tamanoi, F.; Zink, J.I. Drug Release from Three-Dimensional Cubic Mesoporous Silica Nanoparticles Controlled by Nanoimpellers. Z. Anorg. Allg. Chem. 2014, 640, 588-594. [CrossRef]

21. Li, Z.; Barnes, J.C.; Bosoy, A.; Stoddart, J.F.; Zink, J.I. Mesoporous silica nanoparticles in biomedical applications. Chem. Soc. Rev. 2012, 41, 2590-2605. [CrossRef] [PubMed]

22. Tang, Q.; Xu, Y.; Wu, D.; Sun, Y.; Wang, J.; Xu, J.; Deng, F. Studies on a new carrier of trimethylsilyl-modified mesoporous material for controlled drug delivery. J. Control. Release 2006, 114, 41-46. [CrossRef] [PubMed]

23. Rama Rao, G.V.; López, G.P.; Bravo, J.; Pham, H.; Datye, A.K.; Xu, H.F.; Ward, T.L. Monodisperse mesoporous silica microspheres formed by evaporation-induced self assembly of surfactant templates in aerosols. Adv. Mater. 2002, 14, 1301-1304. [CrossRef]

24. Brinker, C.J.; Lu, Y.; Sellinger, A.; Fan, H. Evaporation-induced self-assembly: Nanostructures made easy. Adv. Mater. 1999, 11, 579-585. [CrossRef]

25. Lu, Y.; Fan, H.; Stump, A.; Ward, T.L.; Rieker, T.; Brinker, C.J. Aerosol-assisted self-assembly of mesostructured spherical nanoparticles. Nature 1999, 398, 223-226. [CrossRef]

26. Durfee, P.N.; Lin, Y.-S.; Dunphy, D.R.; Muñiz, A.E.J.; Butler, K.S.; Humphrey, K.R.; Lokke, A.J.; Agola, J.O.; Chou, S.S.; Chen, I.-M.; et al. Mesoporous silica nanoparticle-supported lipid bilayers (protocells) for active targeting and delivery to individual leukemia cells. ACS Nano 2016, 10, 8325-8345. [CrossRef]

27. Butler, K.S.; Durfee, P.N.; Theron, C.; Ashley, C.E.; Carnes, E.C.; Brinker, C.J. Protocells: Modular mesoporous silica nanoparticlesupported lipid bilayers for drug delivery. Small 2016, 12, 2173-2185. [CrossRef]

28. Villegas, M.R.; Baeza, A.; Noureddine, A.; Durfee, P.N.; Butler, K.S.; Agola, J.O.; Brinker, C.J.; Vallet-Regí, M. Multifunctional protocells for enhanced penetration in 3D extracellular tumoral matrices. Chem. Mater. 2018, 30, 112-120. [CrossRef]

29. Dengler, E.C.; Liu, J.; Kerwin, A.; Torres, S.; Olcott, C.M.; Bowman, B.N.; Armijo, L.; Gentry, K.; Wilkerson, J.; Wallace, J.; et al Mesoporous silica-supported lipid bilayers (protocells) for DNA cargo delivery to the spinal cord. J. Control. Release 2013, 168, 209-224. [CrossRef]

30. Kelly, J.T.; Asgharian, B.; Kimbell, J.S.; Wong, B.A. Particle deposition in human nasal airway replicas manufactured by different methods. Part II: Ultrafine particles. Aerosol Sci. Technol. 2004, 38, 1072-1079. [CrossRef]

31. Tao, C.; Yang, K.; Zou, X.; Yan, H.; Yuan, X.; Zhang, L.; Jiang, B. Double-layer tri-wavelength hydrophobic antireflective coatings derived from methylated silica nanoparticles and hybrid silica nanoparticles. J. Sol-Gel Sci. Technol. 2018, 86, 285-292. [CrossRef]

32. Hasan, M.; Messaoud, G.B.; Michaux, F.; Tamayol, A.; Kahn, C.J.; Belhaj, N.; Linder, M.; Arab-Tehrany, E. Chitosan-coated liposomes encapsulating curcumin: Study of lipid-polysaccharide interactions and nanovesicle behavior. RSC Adv. 2016, 6, 45290-45304. [CrossRef]

33. Gangwar, R.K.; Tomar, G.B.; Dhumale, V.A.; Zinjarde, S.; Sharma, R.B.; Datar, S. Curcumin conjugated silica nanoparticles for improving bioavailability and its anticancer applications. J. Agric. Food Chem. 2013, 61, 9632-9637. [CrossRef]

34. Jiang, X.; Ward, T.L.; Cheng, Y.-S.; Liu, J.; Brinker, C.J. Aerosol fabrication of hollow mesoporous silica nanoparticles and encapsulation of L-methionine as a candidate drug cargo. Chem. Commun. 2010, 46, 3019-3021. [CrossRef]

35. Chen, F.; Xu, G.-Q.; Hor, T.A. Preparation and assembly of colloidal gold nanoparticles in CTAB-stabilized reverse microemulsion. Mater. Lett. 2003, 57, 3282-3286. [CrossRef]

36. Jayanthi, G.; Zhang, S.; Messing, G.L. Modeling of solid particle formation during solution aerosol thermolysis: The evaporation stage. Aerosol Sci. Technol. 1993, 19, 478-490. [CrossRef]

37. Min, J.; Wang, F.; Cai, Y.; Liang, S.; Zhang, Z.; Jiang, X. Azeotropic distillation assisted fabrication of silver nanocages and their catalytic property for reduction of 4-nitrophenol. Chem. Commun. 2014, 51, 761-764. [CrossRef]

38. Bolouki, A.; Rashidi, L.; Vasheghani-Farahani, E.; Piravi-Vanak, Z. Study of mesoporous silica nanoparticles as nanocarriers for sustained release of curcumin. Int. J. Nanosci. Nanotechnol. 2015, 11, 139-146. 